\title{
Analysis of Efficiency, Thermal Withstanding Capacity and Electromagnetic Interference of Three Phase Squirrel Cage Induction Motor Coated with $\mathrm{SiO}_{2} \& \mathrm{TiO}_{2}$ NanoComposite Filled Enamel
}

\author{
D. Edison Selvaraj, \\ Department of Electrical and \\ Electronics Engineering, \\ Mepco Schlenk Engineering \\ College, \\ Sivakasi, India.
}

\author{
Dr. C. Pugazhendhi Sugumaran, \\ Division of High Voltage \\ Engineering, \\ College of Engineering, Guindy, \\ Anna University, Chennai, \\ India.
}

\author{
\{B. GuruPrakash, R. Vishnu \\ Prakash, E. Muthupandi, R. \\ Balakumar\} \\ Department of Electrical and \\ Electronics Engineering, \\ Mepco Schlenk Engineering \\ College, \\ Sivakasi, India.
}

\begin{abstract}
Three phase induction motors consume $60 \%$ of industrial electricity. Just $1 \%$ increase in efficiency of all the motors in India will save $500 \mathrm{MW}$ powers which needs the initial generation cost of 2000 crores. Actions were taken to use the enamel filled with $\mathrm{SiO} 2$ and $\mathrm{TiO} 2$ nanocomposite as the coating for the induction motor to improve its efficiency. The efficiency of the induction motor was increased by $5 \%$ by adding nanocomposites of $\mathrm{SiO} 2$ and $\mathrm{TiO} 2(1: 3)$ to the enamel used as the coating for the windings of the three phase squirrel cage induction motor. Heat run test was performed on electrical machines to determine the total loss of energy dissipated as heat. The addition of nanocomposites to the enamel has increased the temperature withstanding capacity of the induction motor. The values of electromagnetic inference produced by normal induction motor and nano coated induction motor was also measured and analyzed. There was a reduction of 15 to $60 \%$ in the values of the electromagnetic interference produced by the normal induction motor when compared to that of nanocomposite filled enamel coated induction motor at various distances. This method can be used as one of the method to reduce the electromagnetic interference by the induction motors.
\end{abstract}

\section{INTRODUCTION}

Induction motors are widely used in fans, centrifugal pumps, blowers, lifts, cranes, hoists and so on. The efficiency of the induction motor depends upon the insulation used. For motors, the enamel is used for three purposes: impregnation, coating and adhesion. The efficiency of the induction motor can be increased by adding the nanofillers with the enamel which is used as coating for the windings of the motor. In this paper, the efficiency of the normal three phase squirrel cage induction motor and the nanocomposite $\mathrm{SiO}_{2}$ and $\mathrm{TiO}_{2}$ in 1:3 filled enamel coated three phase squirrel cage induction motor was analyzed and the results were compared with each other. Heat run test was performed on electrical machines to determine the total loss of energy dissipated as heat. It was a well-known fact that the operating temperature of an electric machine has a very strong relationship with the life duration of the insulation. The insulating enamel mostly used for coating the machine windings were organic in nature, and were adversely affected by thermal decomposition. The dielectric losses will depend upon the dielectric properties of the insulation. These losses will depend upon the breakdown strength, partial discharge characteristics, frequency, type of applied voltage, intensity of electric field and loss tangent. This paper also focuses on the reduction of the electromagnetic interference in the induction motor by coating the enamel which is filled with nanocomposites of $\mathrm{SiO}_{2}$ and $\mathrm{TiO}_{2}$ in 1:3.

www.ijsea.com

\section{DESIGN OF INDUCTION MOTOR}

The design of the induction motor involves the following details:

1. Design of Main dimensions

2. Number of stator slots

3. Turns per Phase

4. Number of Coils

5. Type of winding

\subsection{Design of Main dimensions}

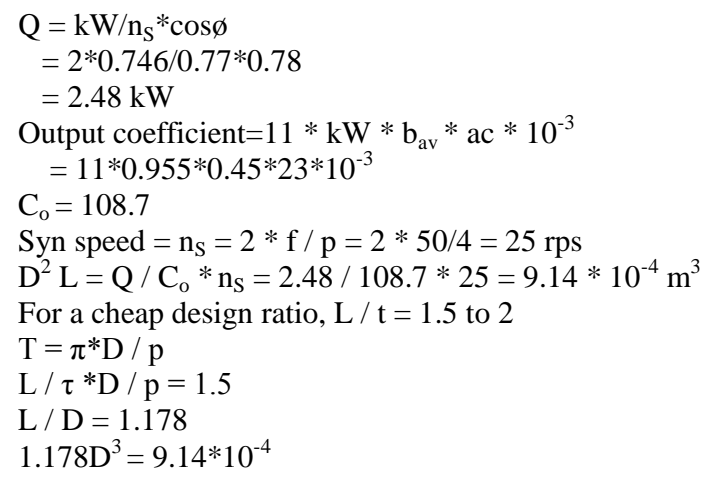


$\mathrm{D}=0.091 \mathrm{~m}$

$0.091^{2} * \mathrm{~L}=9.14 * 10^{-4}$

$\mathrm{L}=0.1103 \mathrm{~m}$

$\tau=\pi * \mathrm{D} / \mathrm{p}=0.07147 \mathrm{~m}$

Pole pitch $=0.07147 \mathrm{~m}$

Radial duct $=10 \mathrm{~mm}$

Net length $=\mathrm{L}_{\mathrm{t}}=0.9 * 0.113=0.09027 \mathrm{~m}$

\subsection{Number of Stator Slots}

Taking slot per pole phase $=\mathrm{q}_{\mathrm{S}}=3$

Total no of stator slot $\mathrm{s}_{\mathrm{s}}=3 * 4 * 3=36$

Stator slot pitch $=y_{\mathrm{ss}}=\pi * \mathrm{D} / \mathrm{s}_{\mathrm{s}}=0.7941 \mathrm{~m}$

Total no of stator Cond $=6 * \mathrm{t}_{\mathrm{s}}=3195$

Conductor per slot $\mathrm{z}_{\mathrm{ss}}=3195 / 36=89$

Actual no of turns per phase,

$\mathrm{t}_{\mathrm{s}}=36 * 89 / 2 * 3=534$

\subsection{Turns per phase}

$\emptyset_{\mathrm{m}}=\mathrm{b}_{\mathrm{av}} * \mathrm{~L} * \tau=0.45 * 0.1103 * 0.0714$

$\emptyset_{\mathrm{m}}=3.543 * 10^{-3}$ Weber

Stator voltage per phase $\mathrm{E}_{\mathrm{s}}=400 \mathrm{~V}$

Stator turns per phase $\mathrm{t}_{\mathrm{s}}=\mathrm{E}_{\mathrm{s}} / 4.44 \mathrm{f} \emptyset_{\mathrm{m}} \mathrm{kW}$

$$
t_{s}=532.51
$$

\subsection{Number of Coils}

No. of coil $=36 / 2=18$

No. of coil per phase $=18 / 3=6$

\subsection{Type of winding used for different slots}

1 to 8 slot (single layer winding)

36 to 7 slot (double layer winding)

\section{PREPARATION NANOFILLERS AND COATING OF THE NANOCOMPOSITE FILLED ENAMEL}

The micropowders of $\mathrm{SiO}_{2}$ and $\mathrm{TiO}_{2}$ were crushed into nanopowders by Ball Mill method [8] [12]. The SEM images of $\mathrm{SiO}_{2}$ and $\mathrm{TiO}_{2}$ before and after Ball Mill show the particle size of the powders. The particle size was augment by SEM images. The nanopowders of $\mathrm{SiO}_{2}$ and $\mathrm{TiO}_{2}$ were taken in the proportion of $1: 3$. Then, the nanocomposites of $\mathrm{SiO}_{2}$ and $\mathrm{TiO}_{2}$ taken in 1:3 were mixed with the enamel by using ultrasonic vibrator. Further, this enamel was coated on the windings of the three phase squirrel cage induction motor. The specifications of the three phase squirrel cage induction motor were shown below in the table 1. Figure 1 shows the Nanocomposite filled enamel coated induction motor
Table 1 Specifications of the three phase squirrel cage induction motor

\begin{tabular}{|l|l|}
\hline Quantity & Rating \\
\hline Power & $1.5 \mathrm{HP}$ \\
\hline Speed & $1450 \mathrm{rpm}$ \\
\hline Current & $3.45 \mathrm{~A}$ \\
\hline Voltage & $415 \mathrm{~V}$ \\
\hline
\end{tabular}

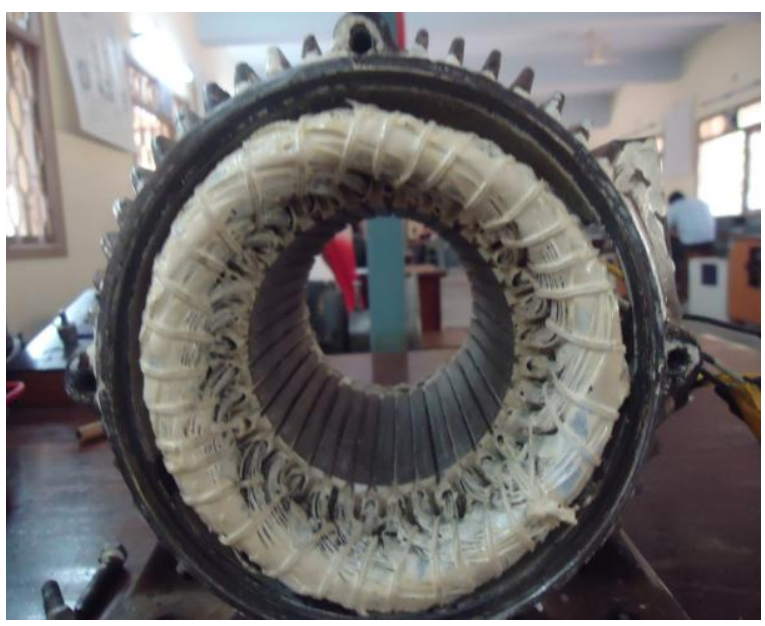

Figure 1 Nanocomposite filled enamel coated induction motor

\section{EXPERIMENTAL ANALYSIS}

\subsection{Performance Analysis of Squirrel Cage Induction Motor - Circle Diagram Method}

This analysis was done by doing open and short circuit test as shown in the figure2. By calculating the open and short circuit current and voltage the losses were found using cirvle diagram method. From the circle diagram it was found that the losses were reduced in nano coated motor. It was shown in the table 2 and 3.

Table 2 Open circuit and short circuit test readings for ordinary induction motor

\begin{tabular}{|l|l|l|l|}
\hline $\begin{array}{l}\text { Open } \\
\text { circuit test }\end{array}$ & Voc & Ioc & Woc \\
\cline { 2 - 4 } & 415 & 1.9 & 176 \\
\cline { 2 - 4 } $\begin{array}{l}\text { Short } \\
\text { circuit test }\end{array}$ & Vsc & Isc & Wsc \\
\cline { 2 - 4 } & 90 & 3.45 & 360 \\
\hline
\end{tabular}


Table 3 Open circuit and short circuit test readings for Nano coated induction motor

\begin{tabular}{|l|l|l|l|}
\hline $\begin{array}{l}\text { Open } \\
\text { circuit test }\end{array}$ & Voc & Ioc & Woc \\
\cline { 2 - 4 } & 415 & 1.9 & 110 \\
\cline { 2 - 4 } $\begin{array}{l}\text { Short } \\
\text { circuit test }\end{array}$ & Vsc & Isc & Wsc \\
\cline { 2 - 4 } & 90 & 3.45 & 320 \\
\hline
\end{tabular}

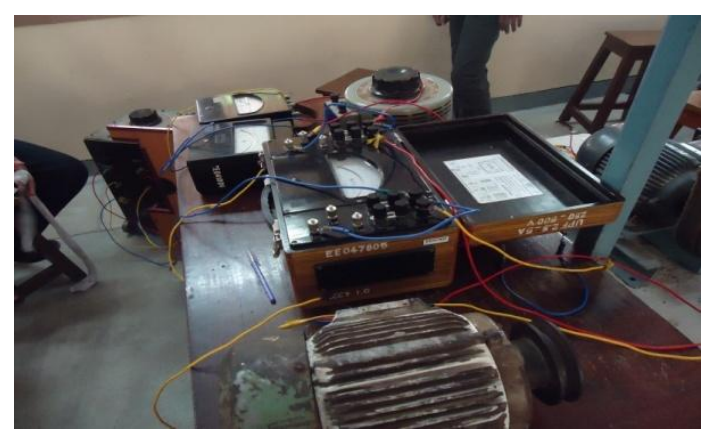

Figure 2 Snap shot of open and short circuit test

Efficiency was analyzed by conducting load test in ordinary as well stator enameled with nano composite motor. The results obtained were successful for our nano coated motor. The efficiency of our nano coated motor increased to 4 percent. This is mainly due to reduction of dielectric losses in Nano coated motor. The readings were calculated for various slip values and shown in table 4 .

Table 4 Efficiency comparison for ordinary and nano coated motor

\begin{tabular}{|l|l|l|}
\hline Slip & $\begin{array}{l}\text { Normal IM } \\
\text { efficiency }\end{array}$ & $\begin{array}{l}\text { Nano coated IM } \\
\text { efficiency }\end{array}$ \\
\hline 0.02 & 77 & 83.5 \\
\hline 0.04 & 75.4 & 82 \\
\hline 0.06 & 74.04 & 77 \\
\hline 0.08 & 68.15 & 73 \\
\hline 0.1 & 63 & 69 \\
\hline
\end{tabular}

\subsection{Performance Analysis of Squirrel Cage Induction Motor - Direct Loading Method}

The load test was conducted and the output power ,current, efficiency, powerfactor and speed of the induction induction was measured. The maximum efficiency obtained from an ordinary induction motor was $78 \%$. The maximum efficiency obtained from nano coated induction motor was $83 \%$.

\subsection{Temperature Test}

Heat run test was performed on electric machines to determine the total loss of energy dissipated as heat. It was wWw.ijsea.com a well-known fact that the operating temperature of an electric machine has a very strong relationship with the life duration of the insulation. Heat run tests were conducted on this motor as per IEC 60851. The temperature of the motor was measured under different conditions and the readings were shown in the tables 5 and 6.

Table 5 Measurement of temperature on stator windings of the motor (without fan) connected to resistive load

\begin{tabular}{|l|l|l|}
\hline $\begin{array}{l}\text { Time in } \\
\text { minutes }\end{array}$ & $\begin{array}{l}\text { Temperature } \\
\text { of ordinary } \\
\text { motor }\end{array}$ & $\begin{array}{l}\text { Temperature } \\
\text { of nano } \\
\text { coated motor }\end{array}$ \\
\hline 0 & 36 & 36 \\
\hline 2 & 39 & 36.5 \\
\hline 4 & 42 & 37 \\
\hline 6 & 44 & 38.5 \\
\hline 8 & 46 & 40 \\
\hline 10 & 48 & 42 \\
\hline 12 & 50 & 45 \\
\hline 14 & 52 & 46.5 \\
\hline 16 & 54 & 47 \\
\hline 18 & 55.5 & 49 \\
\hline 20 & 57 & 49.5 \\
\hline 22 & 58 & 50.5 \\
\hline 24 & 59.5 & 52 \\
\hline 26 & 61 & 53.5 \\
\hline 28 & 63 & 55 \\
\hline 30 & 64.5 & 56 \\
\hline & & \\
\hline
\end{tabular}

\subsection{Experimental Analysis of Electromagnetic Interference}

The electromagnetic fields are force fields, carrying energy and capable of producing an action at a distance. These fields have characteristics of both waves and particles. An electric current flowing in a wire or coil produces its own magnetic field. The electromagnetic interference will also depend upon the dielectric and magnetic materials used in the motor. The electric field will depend upon the dielectric materials and the magnetic field will depend upon the magnetic materials. But as per Maxwell's equation, there was an inter-relation between the electric and magnetic field. Poisson's equation is called as Electrostatic governing equation and Helmholtz equation is called as Electromagnetic governing equation for the time varying field. The electromagnetic interference was measured by 
Table 6 Measurement of temperature on stator windings of the motor (with fan) connected to resistive load

\begin{tabular}{|l|l|l|}
\hline $\begin{array}{l}\text { Time in } \\
\text { minutes }\end{array}$ & $\begin{array}{l}\text { Temperature } \\
\text { of ordinary } \\
\text { motor }\end{array}$ & $\begin{array}{l}\text { Temperature } \\
\text { of nano } \\
\text { coated motor }\end{array}$ \\
\hline 0 & 33 & 33 \\
\hline 2 & 34 & 33.5 \\
\hline 4 & 35.5 & 34 \\
\hline 6 & 37 & 34.5 \\
\hline 8 & 38.5 & 35 \\
\hline 10 & 40 & 35.5 \\
\hline 12 & 41 & 36 \\
\hline 14 & 42 & 37 \\
\hline 16 & 43 & 38 \\
\hline 18 & 44 & 39 \\
\hline 20 & 45 & 39.5 \\
\hline 22 & 46 & 40 \\
\hline 24 & 47 & 41 \\
\hline 26 & 48 & 42 \\
\hline 28 & 49.5 & 43.5 \\
\hline 30 & 51 & 44 \\
\hline
\end{tabular}

means of Gauss meter and Tesla meter. Table 7 shows the values of electromagnetic inference produced by normal induction motor and nano coated induction motor in terms of Gauss and Tesla. From these measurements, it was observed that there was a reduction of 15 to $60 \%$ in the values of the electromagnetic interference produced by the normal induction motor when compared to that of nanocomposite filled enamel coated induction motor at various distances. Hence, the effect of electromagnetic interference was reduced to the humans, other electrical devices, communication devices and measuring instruments.

\section{CONCLUSIONS}

The following observations were clear as per this study:

1. The efficiency of the induction motor was increased by $5 \%$ by adding nano composites of $\mathrm{SiO}_{2}$ and $\mathrm{TiO}_{2}(1: 3)$ to the enamel used as the coating for the windings of the three phase squirrel cage induction motor.

2. The speed fluctuations were also less and smooth when compared to that of the ordinary induction motor.

3. The addition of nanocomposites to the enamel has increased the temperature withstanding capacity of the induction motor. Hence the life time of the motor will be increased.
4. There was a reduction of 15 to $60 \%$ in the values of the electromagnetic interference produced by the normal induction motor when compared to that of nanocomposite filled enamel coated induction motor at various distances.

The performance of the induction motor as well as several DC motors can also be improved by using the enamel filled with various nanofillers such as $\mathrm{TiO}_{2}$, $\mathrm{SiO}_{2}, \mathrm{Al}_{2} \mathrm{O}_{3}, \mathrm{ZrO}_{2}$ and $\mathrm{ZnO}$.

Table 7 Measurement of Electromagnetic Interference

\begin{tabular}{|c|c|c|c|c|}
\hline \multirow{2}{*}{ Distance } & \multicolumn{2}{|c|}{ Ordinary motor } & \multicolumn{2}{c|}{ Nanocoated motor } \\
\cline { 2 - 5 } & Tesla & Gauss & Tesla & Gauss \\
\hline $30 \mathrm{~cm}$ & 0.07 & 0.7 & 0.03 & 0.3 \\
\hline $25 \mathrm{~cm}$ & 0.08 & 0.8 & 0.06 & 0.6 \\
\hline $15 \mathrm{~cm}$ & 0.18 & 1.8 & 0.15 & 1.5 \\
\hline $10 \mathrm{~cm}$ & 1.18 & 12.3 & 0.80 & 7.9 \\
\hline $5 \mathrm{~cm}$ & 6.24 & 58.6 & 4.69 & 46.14 \\
\hline $1 \mathrm{~cm}$ & 19.13 & 189 & 17.14 & 171.5 \\
\hline On the casing & 12.05 & 119.2 & 9.42 & 98.5 \\
\hline
\end{tabular}

\section{ACKNOWLEDGEMENT}

Thank God and His almighty power to finish His research work by using me, my project guide and my students for His ultimate work.

\section{REFERENCES}

1. Dieter Kind and Hermann Kamer, "High Voltage Insulation Technology" 1985.

2. M S Naidu and V Kamaraju, "High Voltage Engineering" Solid dielectrics used in practice pp $106-122$.

3. B. Tareev "Physics of Dielectric Materials" Tests for thermal ageing pp $234-235$.

4. IEC 61251: Electrical insulating materials - A.C. voltage endurance evaluation. IEC, Geneva, 1993.

5. E. Kuffel, W.S. Zaengl and J. Kuffel, "High voltage engineering fundamentals" Partial discharge measurements.

6. J. W. Mackersie, M. J. Given and R A. Fouracre, "The electrical properties of filled and unfilled commercial epoxy resins", IEE 2000.

7. K. Inuzuka, H. Inano, N. Hayakawa, T. Hirose, M. Hamaguchi, and H. Okubo, " Partial discharge 
International Journal of Science and Engineering Applications (IJSEA)

Volume 1 Issue 1, 2012

characteristics of nanocomposite enameled wire for inverter fed motor," 2006Annu. Rep. Conf. Elect. Insul. Dielect. Phenomena, Kansas City, 2006, pp. 594-597.

8. Pugazhendhi Sugumaran. C, Mohan. M.R and Udayakumar. K, "Investigation of Dielectric and Thermal Properties of Nano-filler ( $\mathrm{ZrO} 2)$ Mixed Enamel", IEEE Transaction on Dielectrics and Electrical Insulation: Vol.17, No.6, 2010.

9. Hulya Kirkici, Mert Serkan, Koppisetty, "Nanodielectric Materials in Electrical Insulation Application", IEEE, 2005.

10. Takahiro Imai, Gen Komiya, Kiyoko Murayama, Tamon Ozaki, "Improving Epoxy-based Insulating Materials with Nano-fillers toward Practical Application", IEEE 2008.

11. Guoqin Zhang, Guangning $\mathrm{Wu}$, Laisheng Tong, Enguang, " Study of $\mathrm{Nano}_{\mathrm{TiO}}$ Filler in the Corona resistant Magnetic Wire Insulation Performance of Inverter-fed Motor", Proceedings of international Symposium on Electrical Insulating Materials, June 5-9, 2005, Kitakyushu, Japan A3-8, 2005.

12. Edison Selvaraj. D, Pugazhendhi Sugumaran. C and SivaPrakash. A, "Characterization of Electrical and Thermal Properties of Enamel Filled with Carbon Nanotubes”, PEIE 2012, LNEE, pp. 496-502, 2012. 